\section{EDITO RIA L}

TOMO 58

Número 1

Enero-Febrero

2005

\section{ARCHIVOS ESPAÑOLES DE UROLOGIA}

FUN DADO S PO R E. PEREZ CASTRO, A. PUIG VERT G O RRO Y

L. CIFUEN TES DELATTE

Director / Editor: E. Pérez-C astro Ellendt

Editor Asociado: L. M artínez-Piñeiro Lorenzo

EDITO RIA L

\title{
Influencia de la consulta por disfunción erectil en la práctica Urológica actual y futura.
}

Los extraordinarios cambios que se han producido en los últimos 30 años en la evaluación del enfermo con impotencia y en sus opciones terapéuticas, no sólo representan un extraordinario progreso científico en este concreto campo del conocimiento urológico, sino que han influido notablemente en nuestra especialidad como cuerpo de doctrina y como práctica médica. Pero lo que hasta ahora hemos visto los que tenemos ya una práctica urológica prolongada, es sólo la punta del iceberg que anuncia los importantes cambios que van a producirse en los próximos años. El urólogo, consciente de estos cambios, desea conocer, si no quiere quedar finalmente apartado de uno de los compromisos profesionales más interesantes e integradores de su especialidad, hasta donde debe alcanzar la actuación médica que ciertamente la actualidad social y sanitaria le exige en relación con esta patología.

En los años setenta el estudio del enfermo impotente quedaba reducido a concretas pruebas relacionadas fundamentalmente con el órgano motivo de la disfunción. A sí, la exploración física del área genital, era inexcusable y cuidadosa, intentando descubrir hallazgos singulares, frente a la normalidad como regla. La población que consultaba en aquella época era relativamente joven y pudorosa y la mayoría de ellos era considerados como enfermos psíquicos. No obstante la exploración del área genital buscaba algún argumento anatómico que justificase la impotencia y en los años setenta realizamos numerosas cavernosografias dinámicas buscando alguna pequeña alteración como fibrosis zonales, que difícilmente eran encontradas, o escapes venosos de difícil y controvertida interpretación. Pero ciertamente conseguimos una gran colección de modelos de patologías estructurales, relacionadas con la enfermedad de la Peyronie, y otros tipos de malformaciones congénitas y traumáticas. Las ofertas terapéuticas de la época era muy reducidas y el recurso a los andrógenos frecuente, con escaso éxito. La gran solución llegó con las prótesis que alcanzaron un inmediato éxito y utilización. En el año 74 inmediatamente después del Congreso de la Asociación Americana de Urología celebrado en Miami, donde los doctores Small y Carrión presentaron su modelo de prótesis intracavernosa, y su muy reducida experiencia inicial, nosotros consideramos que 
era el momento de ofrecerle ayuda eficaz a un joven taxista que tres años atrás, a consecuencia de un traumatismo perineal, habia quedado con impotencia total. Fue nuestra primera experiencia, con un exito extraordinario, cuya información alcanzó a todo el servicio de urología ya que aquél taxista presumía públicamente de sus éxitos tras la colocación de la prótesis. Seguramente fue la primera prótesis de impotencia que se colocó en España y su publicación con Ricardo Espuela no pudo finalmente realizarse por el grupo de J. García Peri (Promociones M édicas) a donde se envió el texto, porque se canceló su publicación en aquellos días. Un interesante episodio de aquella primera operación fue que durante la anestesia general, el anestesista, que se había formado en Londres, nos comentó que aquella era la operación que hacía su amigo el Dr.BIHERI, un cirujano plástico egipcio que había conseguido una considerable casuística, que no publicó hasta años más tarde. Efectivamente, la idea de una prótesis intracavernosa constituía una auténtica revolución y motivo de secreto profesional, frente a las primeras prótesis extracavernosas, de fácil colocación pero de reducida eficacia como la propuesta por el Drs. W Goodwin y Robert Pearman de Los Angeles, cuya experiencia tuvimos ocasión de comprobar a mediados de los años sesenta. En cualquier caso, lo que nos interesa resaltar aquí es que el diagnóstico y tratamiento de la impotencia en los años setenta constituía un misterioso mundo especializado sobre el que construyeron los andrólogos una parte importante de su especialidad, que junto a otros conocimientos y habilidades supuso un intento de segregación de la urología, fallido por varias razones y entre ellas por los cambios que se han producido en el acercamiento a la disfunción eréctil.

¿Q ué está sucediendo ahora con la disfunción eréctil dentro y fuera de las consultas urológicas?. La llegada de los inhibidores de la fosfodiesterasa (PDE5) ha convertido en un éxito el tratamiento de la disfunción eréctil y facilita el acceso de todos los enfermos al médico quien al mismo tiempo se encuentra más solicitado debido, precisamente, a la eficacia de esta nueva terapéutica. Los siguientes factores han convertido la consulta de impotencia en un área de enormes solicitudes y demanda: La mayor exigencia de la población que ha perdido, en cierto modo, el pudor por este tipo de deficiencia: El incremento de la población longeva que supone un extraordinario aumento de la consulta urológica, especialmente por patología prostática, que simultáneamente ha aumentado la demanda de información y tratamiento de la impotencia, ya que es la edad el factor de riesgo más notable de esta deficiencia: La consulta urológica por éstos y otros motivos ha aumentado también de manera considerable e incidentalmente es más fácil hablar de sexualidad ahora que hace años. Tenemos, además, en este momento, la evidencia de que la disfunción eréctil puede ser el primer síntoma de una enfermedad sistémica y más en concreto de enfermedad endotelial. En definitiva las consultas urológicas se ven actualmente desbordadas por la demanda de una patología que hasta hace años constituía un proceso oculto e íntimo. En compensación a este incremento la consulta de impotencia se ha generalizado y la medicina primaria se ha convertido, en algunos países, en la primera línea de consulta y tratamiento de este proceso. Ciertamente se comprueba que el urólogo está recibiendo ya enfermos más complejos, que no responden al tratamiento oral, es decir, a las facilidades terapéuticas de primera línea, o resisten iniciativas básicas propuestas por otras especialidades, porque también enfermos diabéticos, hipertensos, cardiópatas, neurológicos, etc., así como con enfermedades metabólicas y de otra naturaleza, son atendidos por sus respectivos especialistas. 
¿Qué hacer?. Como sucedió en su día con la litiasis renal el urólogo no pueden quedar reducido a un simple cirujano, a ún simple litotomista, aunque la cirugía peneana siga constituyendo, por varias razones, un capítulo importante de actividad urológica. La lectura importante de este cambio, que ya se reconoce en muchos ambientes asistenciales, es que el enfermo consulta primaria y prioritariamente al urólogo. Es el urólogo el que tiene el paciente y sólo en un reducido número de casos cuando se le refiere. La consulta por disfunción eréctil seguramente constituye uno de los argumentos básicos que justifica la nueva tendencia a considerar al urólogo como "el generalista del varón. Revitaliza esta nueva consideración el compromiso médico de la urología como especialidad médico-quirúrgica. Pero este acontecimiento nos llega rodeado de un extraordinario interés por que la disfunción eréctil, como se verá en el artículo que acompaña esta editorial, es un campo enormemente atractivo desde el punto de vista biológico, terapéutico y antropológico en el sentido de que nos acerca al enfermo en su faceta más intima y humana, lejos de la frialdad burocrática y procesal de la medicina actual.

La vieja broma, tantas veces contada, de Geoffrey Chisholm se está convirtiendo, paradójicamente, en cierta. Decía Chisholm que durante los Congresos de U rología debía ponerse en los urinarios del Palacio del Congreso, justo en esa pared blanca y no muy limpia a la que se mira con displicencia mientras se orina, una gran pancarta con el siguiente título ¡Urólogos, el futuro de la urología está en tu mano!. Por supuesto, el pene no ha perdido su simbolismo como órgano de la potencia pero al comprobarse que estas disfunciones son en un elevado porcentaje de casos consecuencia de alteraciones generalizadas, se concede al urólogo la oportunidad de un compromiso asistencial que supera en mucho lo oferta de una simple enfermedad de órgano. Y esto implica un notable cambio en la imagen de la consulta urológica y del compromiso asistencial del urólogo. La Urología, especialidad medico-quirúrgica, ve, por ésta y otras razones, reforzado su compromiso médico hasta limites que pueden ampliarse de manera extraordinaria en el futuro inmediato. Pero a un nivel científico y asistencial muy superior al pesimismo surrealista señalado por Joseph Kaufman, con otra frase también históricamente famosa "W e started out as clap Doctors and we'll end up as clap Doctors"!. A hora, ciertamente, nuestro problema es definir hasta donde deben llegar nuestras investigaciones etiopatogénicas en la disfunción eréctil, hasta donde nuestras recomendaciones preventivas y terapéuticas y cuando, como y con quien debemos compartir el cuidado del enfermo impotente.

Fdo. Prof. R. Vela Navarrete 